\title{
Excitatory amino acid receptor blockade within the caudal pressor area and rostral ventrolateral medulla alters cardiovascular responses to nucleus raphe obscurus stimulation in rats
}

\section{N.F. Silva², J.G.P. Pires ${ }^{1}$ \\ M.A. Dantas ${ }^{1}$ and H.A. Futuro Neto ${ }^{1}$}

\author{
1Departamento de Ciências Fisiológicas, Centro Biomédico, \\ Universidade Federal do Espírito Santo, Vitória, ES, Brasil \\ ${ }^{2}$ Associação Educacional de Vitória (FAESA), Vitória, ES, Brasil
}

\section{Correspondence \\ H.A. Futuro Neto \\ Av. Marechal Campos, 1468 \\ 29040-090 Vitória, ES \\ Brasil \\ Fax: + 55-27-3335-7330 \\ E-mail: futuront@ npd.ufes.br \\ Research supported by CNPq and FINEP.}

Received August 7, 2001

Accepted June 24, 2002

\section{Abstract}

Pressor responses elicited by stimulation of the nucleus raphe obscurus (NRO) depend on the integrity of the rostral ventrolateral medulla (RVLM). Therefore, to test the participation of excitatory amino acid (EAA) receptors in the cardiovascular responses evoked by NRO stimulation $(1 \mathrm{~ms}, 100 \mathrm{~Hz}, 40-70 \mu \mathrm{A}$, for $10 \mathrm{~s})$, the EAA antagonist kynurenic acid (Kyn) was microinjected at different sites in the ventrolateral medullar surface $(2.7 \mathrm{nmol} / 200 \mathrm{nl})$ of male Wistar rats (270-320 g, N = 39) and NRO stimulation was repeated. The effects of NRO stimulation were: hypertension $(\triangle \mathrm{MAP}=+43 \pm 1 \mathrm{mmHg}$, $\mathrm{P}<0.01)$, bradycardia $(\Delta \mathrm{HR}=-30 \pm 7 \mathrm{bpm}, \mathrm{P}<0.01)$ and apnea. Bilateral microinjection of Kyn into the RVLM, which did not change baseline parameters, almost abolished the bradycardia induced by NRO stimulation ( $\triangle \mathrm{HR}=-61 \pm 3$ before $v s-2 \pm 3 \mathrm{bpm}$ after Kyn, $\mathrm{P}<0.01, \mathrm{~N}=7$ ). Unilateral microinjection of Kyn into the CVLM did not change baseline parameters or reduce the pressor response to NRO stimulation $(\triangle \mathrm{MAP}=+46 \pm 5$ before $v s+48 \pm 5 \mathrm{mmHg}$ after Kyn, $\mathrm{N}=6$ ). Kyn bilaterally microinjected into the caudal pressor area reduced blood pressure and heart rate and almost abolished the pressor response to $\mathrm{NRO}$ stimulation $(\triangle \mathrm{MAP}=+46 \pm 4 \mathrm{mmHg}$ before $v \mathrm{~s}$ $+4 \pm 2 \mathrm{mmHg}$ after Kyn, $\mathrm{P}<0.01, \mathrm{~N}=7$ ). These results indicate that EAA receptors on the medullary ventrolateral surface play a role in the modulation of the cardiovascular responses induced by NRO stimulation, and also suggest that the RVLM participates in the modulation of heart rate responses and that the caudal pressor area modulates the pressor response following NRO stimulation.

\section{Introduction}

The participation of the nucleus raphe obscurus (NRO) in cardiovascular regulation using electrical stimulation has been demonstrated in various species. For instance,

\section{Key words}

- Raphe nuclei

- Electrical stimulation

- Ventrolateral medulla

- Caudal pressor area

- Excitatory amino acid receptors

- Blood pressure
- Kynurenic acid 
nant. In anesthetized rats, electrical or chemical stimulation of the NRO and other raphe nuclei frequently causes increases in arterial BP $(3,6)$ with wide heart rate (HR) variability. Dreteler et al. (7) demonstrated a rise in $\mathrm{BP}$ as a result of $5-\mathrm{HT}_{1 \mathrm{~A}}$ receptor agonist microinjection into the NRO, and proposed that the related bradycardia was a baroreflex-mediated response. In contrast, Coleman and Dampney (8) observed sympathoinhibition and hypotension evoked by microinjection of L-glutamate into sites within the NRO in anesthetized rabbits.

Anatomical studies of rats have indicated that caudal raphe neurons project either directly to the intermediolateral (IML) cell column (9-11) or by sending axons to sites in the ventrolateral medulla (VLM) (12-14). Therefore, there is no conclusive evidence concerning NRO projections or their precise role in cardiovascular regulation. Campos Jr. et al. (15) showed that the pressor effects caused by stimulating the NRO require an intact rostral ventrolateral medulla (RVLM), an important area in the VLM involved in autonomic control (16), which directly projects to the IML (9). Preliminary results from our laboratory (17) failed to demonstrate direct functional connections between NRO and RVLM. We therefore hypothesized that the NRO might not have monosynaptic connections to the RVLM, and that the responses to NRO stimulation may be mediated by indirect projections to the RVLM.

At least two other areas in the VLM that are involved in autonomic control can influence RVLM activity: the caudal ventrolateral medulla (CVLM) $(18,19)$, a sympathoinhibitory area with projections to the RVLM (20), and the caudal pressor area (CPA) (21), originally described as a hypertensive area in deeply anesthetized or decerebrate animals (22-24). The functional connections between the CPA and the RVLM $(23,25)$ possibly occur via CVLM glutamatergic neurons (26).

The various cardiovascular and respiratory responses evoked by NRO stimulation have been credited to activation of serotonergic neurons (7). However, other neurotransmitters are present in NRO neurons, including excitatory amino acids (EAA; mainly L-glutamate). Since the blockade of $5-\mathrm{HT}_{1-3}$ receptors in the VLM did not block the cardiovascular responses evoked by NRO stimulation (17), the present study was designed to test the possible role of EAAmediated NRO projections to the RVLM, CVLM and CPA in these responses.

\section{Material and Methods}

Male Wistar rats weighing 270-320 g were anesthetized with urethane $(1.2 \mathrm{~g} / \mathrm{kg}$, after induction with ether) injected into the left femoral vein cannulated with a polyethylene catheter (PE50). Supplementary doses of anesthetic were administered whenever necessary, as indicated by the paw pinch reflex and/or by unstable cardiovascular recordings. Arterial BP was recorded through a heparinized $(40 \mathrm{U} / \mathrm{ml})$ saline-filled catheter (PE50) inserted into the left femoral artery and connected to a pressure transducer (Statham P23 Db, Valley View, OH, USA). Pulsatile BP, mean arterial BP (MAP) and HR were recorded with a Gould RS 3400 polygraph. A tracheotomy was performed in all animals and respiration was recorded with a pneumotachograph (Fleish 0000) and a low-pressure transducer (Valadine) connected to the polygraph. Whenever necessary the rats were artificially ventilated (Harvard Rodent Ventilator, South Natick, MA, USA). All cardiovascular and respiratory activity data were digitalized (Biopac MP 100) and stored on a PC hard disk for later processing. Rectal temperature was maintained between $36-37^{\circ} \mathrm{C}$ with a homeothermic blanket (Harvard).

The rats were mounted on a stereotaxic apparatus (Stoelting, Wood Dale, IL, USA) and monopolar isolated cathodal stimulation $(1 \mathrm{~ms}, 100 \mathrm{~Hz}, 40-70 \mu \mathrm{A}$, for $10 \mathrm{~s}$ ) of the NRO (midline, $11.8 \mathrm{~mm}$ AP in relation to the 
bregma, $8 \mathrm{~mm}$ depth) was performed with stainless steel electrodes insulated throughout except at the tip (tip size $30-40 \mu \mathrm{m}$, resistance $15-30 \mathrm{k} \Omega$ ), the anode being a clip attached to a neck muscle. The dorsal surface of the brainstem was exposed by retraction of the skin and muscles at the base of the skull, followed by the removal of the atlantooccipital membrane and portions of the occipital bone. Kynurenic acid (Kyn; $2.7 \mathrm{nmol} /$ $200 \mathrm{nl}$ ) and artificial cerebrospinal fluid (CSF) containing $122 \mathrm{mM} \mathrm{NaCl}, 25.7 \mathrm{mM}$ $\mathrm{NaHCO}_{3}, 1 \mathrm{mM} \mathrm{MgSO}_{4}$, and $1 \mathrm{mM} \mathrm{CaCl}_{2}$, with $\mathrm{pH}$ adjusted to 7.2-7.4, were microinjected bilaterally into the RVLM $(+3 \mathrm{~mm}$ AP in relation to the obex, $1.5 \mathrm{~mm} \mathrm{~L}$ ), CVLM $(+1 \mathrm{~mm}$ AP in relation to the obex, $1.5 \mathrm{~mm}$ $\mathrm{L})$ or CPA (-1 mm AP in relation to the obex, $1.5 \mathrm{~mm} \mathrm{~L}$ ). In a separate group of four animals, Kyn was microinjected unilaterally into the CVLM. Vertical positioning was obtained by slowly lowering both micropipettes placed inside the guide cannulae (which were 6-8 $\mathrm{mm}$ shorter than the micropipettes) until a slight displacement between them was observed (the displacement occurs when the tip of the micropipette touches the pia mater adjacent to the ventral medullar surface; the depth was $0.79 \mathrm{~mm}$ for the RVLM in relation to the dorsal surface of the cerebellum, $0.59 \mathrm{~mm}$ for the CVLM in relation to the dorsal surface of the cerebellum and $0.33 \mathrm{~mm}$ for the CPA in relation to the dorsal surface of the medulla. Therefore the microinjections were applied to the ventral layers of the nuclei).

At least three electrical stimulations of the NRO were performed at 3-min intervals and the means of the measured parameters were considered as controls. Kyn microinjection was performed $\sim 1.5$ min after the last control NRO stimulation and after a period of $\sim 1.5$ min a new series of three NRO stimulations was performed. A separate group of CSF-treated animals was used as timematched controls.

At the end of each experiment the posi- tion of the stimulus or of the microinjection was determined by passing a DC current of 5-20 $\mu \mathrm{A}$ for 1 min (stainless steel electrode anode) or by microinjecting $200 \mathrm{nl} 2 \%$ Evan's blue dye. The animals were then heparinized and transcardially perfused with $200 \mathrm{ml} \mathrm{sa}-$ line solution $(0.9 \% \mathrm{NaCl})$ and a solution of $1 \%$ potassium ferrocyanide in $10 \%$ formaldehyde. The brain was removed and placed in formaldehyde for 7 days. Sites of microinjections or electrical NRO stimulation were identified and plotted on a schematic diagram.

Data are reported as means \pm SEM. Paired or unpaired $t$-tests were used whenever appropriate for statistical comparisons of the means. Two-way ANOVA was used for comparisons between groups. In all cases, the level of significance was set at $\mathrm{P} \leq 0.05$.

\section{Results}

\section{Effect of electrical stimulation of the NRO on arterial blood pressure, heart rate and respiration of anesthetized rats}

In the 39 anesthetized rats studied, basal MAP and HR were $92 \pm 1 \mathrm{mmHg}$ and $384 \pm$ 7 bpm, respectively. Electrical stimulation of a site within the NRO produced an increase of $\mathrm{BP}(\mathrm{MAP}=135 \pm 2, \Delta \mathrm{MAP}=+43$ $\pm 1 \mathrm{mmHg}, \mathrm{P}<0.01, \mathrm{~N}=39$; Figure 1). $\mathrm{HR}$ changes during NRO stimulation were variable, but bradycardia was observed in most animals $(\mathrm{HR}=353 \pm 9, \Delta \mathrm{HR}=-30 \pm 7 \mathrm{bpm}$, $\mathrm{P}<0.01, \mathrm{~N}=39$; Figure 1). The stimulus frequently elicited apnea. These animals were divided into subgroups to test the effects of bilateral microinjections of CSF and Kyn within the RVLM, CVLM or CPA on the responses to NRO stimulation.

\section{Effects of EAA receptor antagonism in the RVLM on the responses to NRO stimulation}

A group of seven rats was used to study the effects of EEA receptor blockade in the 
Figure 1. Mean arterial blood pressure (MAP; panel $A$ ) and heart rate (HR; panel $B$ ) before and after nucleus raphe obscurus (NRO) stimulation. B1, baseline before stimulation. Data are reported as means \pm SEM for all 39 rats. $* \mathrm{P}<0.01$ compared to B1 (Student t-test).

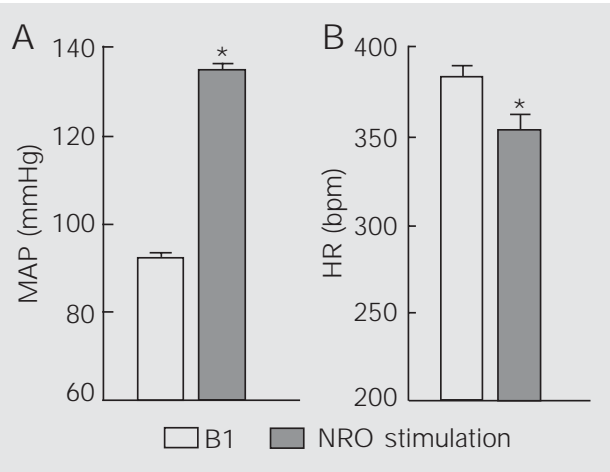

Figure 2. A, Tracings from one rat showing the cardiovascular and respiratory responses to nucleus raphe obscurus (NRO) stimulation $(10 \mathrm{~s}$ at $100 \mathrm{~Hz}, 60$ $\mu \mathrm{A}$, and 1-ms pulse duration) before and after bilateral microinjection of kynurenic acid (Kyn, $2.7 \mathrm{nmol} / 200 \mathrm{nl}$ ) within the rostral ventrolateral medulla (RVLM). $\mathrm{BP}$, pulsatile blood pressure; $M A P$, mean arterial BP; HR, heart rate; Resp, respiration. The triangles denote electrical stimulations, and the arrow indicates microinjection. B, The left representative section shows the location of the NRO stimulation site. The illustration on the right shows the injection site within the RVLM.

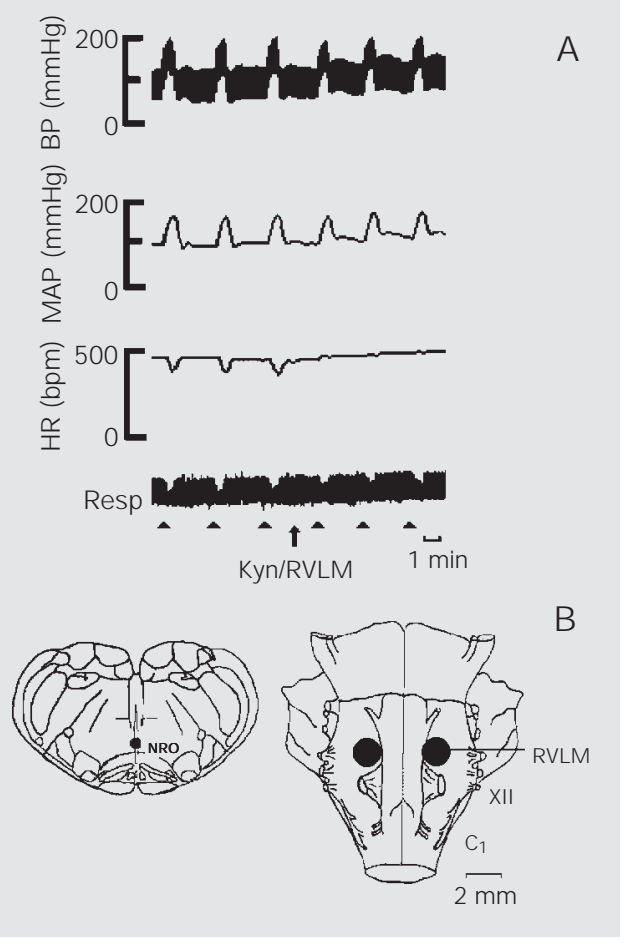

RVLM with Kyn on the cardiovascular responses to NRO stimulation. Bilateral Kyn microinjection did not alter baseline arterial pressure, HR or respiration pattern. Also, pressor and respiratory responses to NRO stimulation were not modified by Kyn (Figure 2). The microinjection produced no significant changes in basal MAP $(94 \pm 3$ to 89 $\pm 3 \mathrm{mmHg}$ ) or in the NRO stimulation pressor responses (135 \pm 3 before Kyn and $131 \pm$ $2 \mathrm{mmHg}$ after Kyn, $\mathrm{N}=7$; Figure 3). On the other hand, although Kyn microinjection did not elicit variations in basal HR (control = $404 \pm 9$, after Kyn $=405 \pm 11$ bpm), it significantly reduced $\mathrm{HR}$ responses to NRO stimulation $(\Delta \mathrm{HR}=-61 \pm 3$ and $-2 \pm 3 \mathrm{bpm}$, before and after Kyn, respectively, $\mathrm{P}<0.01$, $\mathrm{N}=7$; Figure 3). Microinjection of vehicle (artificial CSF) into this area induced no significant changes in any of the parameters analyzed (MAP: $90 \pm 3$ to $91 \pm 4 \mathrm{mmHg}$; $\mathrm{NRO}$ stimulation $=127 \pm 3$ before CSF and $129 \pm 5$ mmHg after CSF; HR: $378 \pm 13$ to $380 \pm 15$ bpm; NRO stimulation $=300 \pm 17$ before CSF and $303 \pm 18$ bpm after CSF; Figure 3 ).

\section{Effects of EAA receptor antagonism in the CVLM on the responses to NRO stimulation}

In another group of animals $(\mathrm{N}=7)$ in which Kyn was microinjected bilaterally within the CVLM, BP increased, HR was not significantly altered and respiration was com-
Figure 3. Effect on mean arterial blood pressure (MAP; panel A) and heart rate ( $\mathrm{HR}$; panel $\mathrm{B})$ of bilateral microinjections of cerebrospinal fluid (CSF, $200 \mathrm{nl}$ ) or kynurenic acid (Kyn, $2.7 \mathrm{nmol} /$ $200 \mathrm{nl})$ within the rostral ventrolateral medulla and effect of electrical nucleus raphe obscurus stimulation (NROS). B1, baseline values; B2, post-drug baseline values. Data are reported as means \pm SEM for 7 rats. $* P<0.01$ compared to the preceding baseline value (Student t-test).

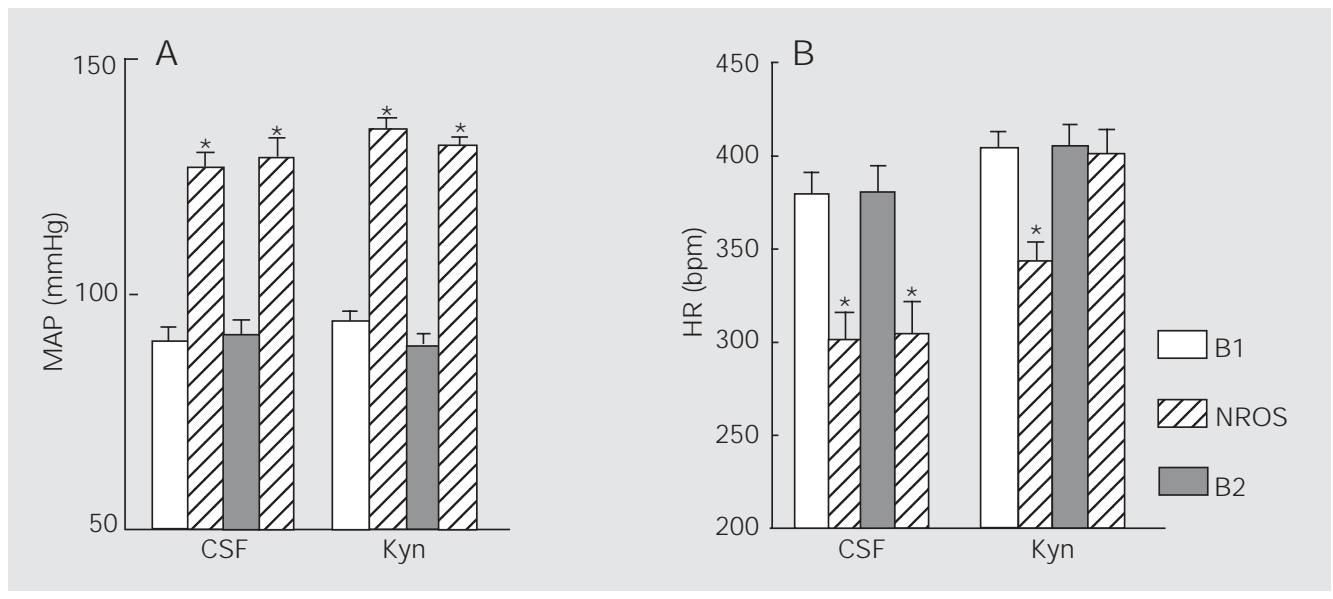


pletely blocked. HR responses were found to be variable; for instance, in Figure 4 one such tracing is shown, where an attenuation of HR was observed.

Statistical analysis of the pooled data (Figure 5) showed that Kyn injected bilaterally into the CVLM provoked an increase in MAP $(89 \pm 3$ to $124 \pm 4 \mathrm{mmHg}, \mathrm{P}<0.01, \mathrm{~N}=$ 7 ), and that the pressor response to NRO stimulation was slightly attenuated ( $\triangle \mathrm{MAP}$ $=+48 \pm 4$ to $+43 \pm 3 \mathrm{mmHg}$ after Kyn, $\mathrm{P}<0.05, \mathrm{~N}=7$ ).

Nonsignificant changes in cardiovascular and respiratory parameters to NRO stimulation were induced by CSF microinjections into the CVLM (baseline: MAP $=91 \pm$ 4 to $92 \pm 5 \mathrm{mmHg}$; NRO stimulation: $\triangle \mathrm{MAP}$ $=+41 \pm 4$ to $+41 \pm 5 \mathrm{mmHg}$; baseline: $\mathrm{HR}=$ $367 \pm 31$ to $369 \pm 29 \mathrm{bpm}$; NRO stimulation: $\Delta \mathrm{HR}=-19 \pm 26$ to $-25 \pm 23 \mathrm{bpm}$, before and after $\mathrm{CSF}$, respectively, $\mathrm{N}=6$ ).

Bilateral Kyn microinjection into the CVLM induced an increase in basal BP and a statistically significant reduction of the pressor response to NRO stimulation. Therefore, a separate group of rats with unilateral Kyn microinjection was used to determine the influence of changes in basal BP on the reduction of NRO responses. After unilateral Kyn injection, which induced a smaller increase in basal BP and did not block respiration, no significant effects were observed on the pressor responses to NRO stimulation $(\triangle \mathrm{MAP}=+46 \pm 5$ before Kyn and $+48 \pm 5$ after Kyn, $N=6$; data not shown). The use of this second group proved that the reduction in the pressor response was due to alteration in basal BP and not to a real blockade of the NRO response.

\section{Effects of EAA receptor antagonism in the CPA on the responses to NRO stimulation}

The cardiovascular and respiratory changes

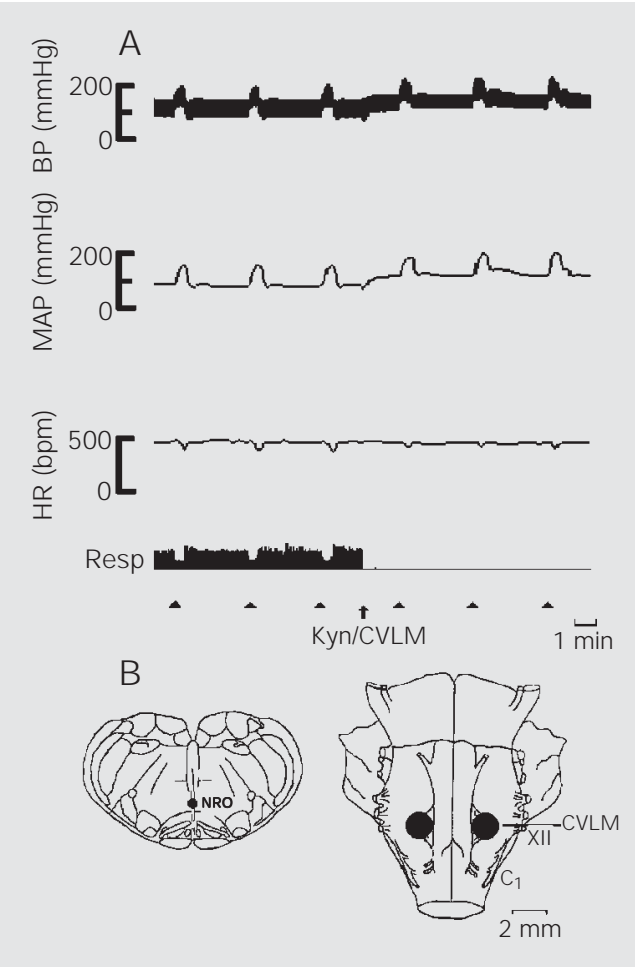

Figure 4. A, Tracings from one rat showing the cardiovascular and respiratory responses to nucleus raphe obscurus (NRO) stimulation $(10 \mathrm{~s}$ at $100 \mathrm{~Hz}, 60$ $\mu \mathrm{A}$, and 1-ms pulse duration) before and after bilateral microinjection of kynurenic acid (Kyn, $2.7 \mathrm{nmol} / 200 \mathrm{nl}$ ) within the caudal ventrolateral medulla (CVLM). BP, pulsatile blood pressure; MAP, mean arterial $\mathrm{BP} ; \mathrm{HR}$, heart rate; Resp, respiration. The triangles denote stimulations, and the arrow indicates microinjection. B, The left representative section shows the location of the NRO stimulation site. The illustration on the right shows the injection site within the CVLM.
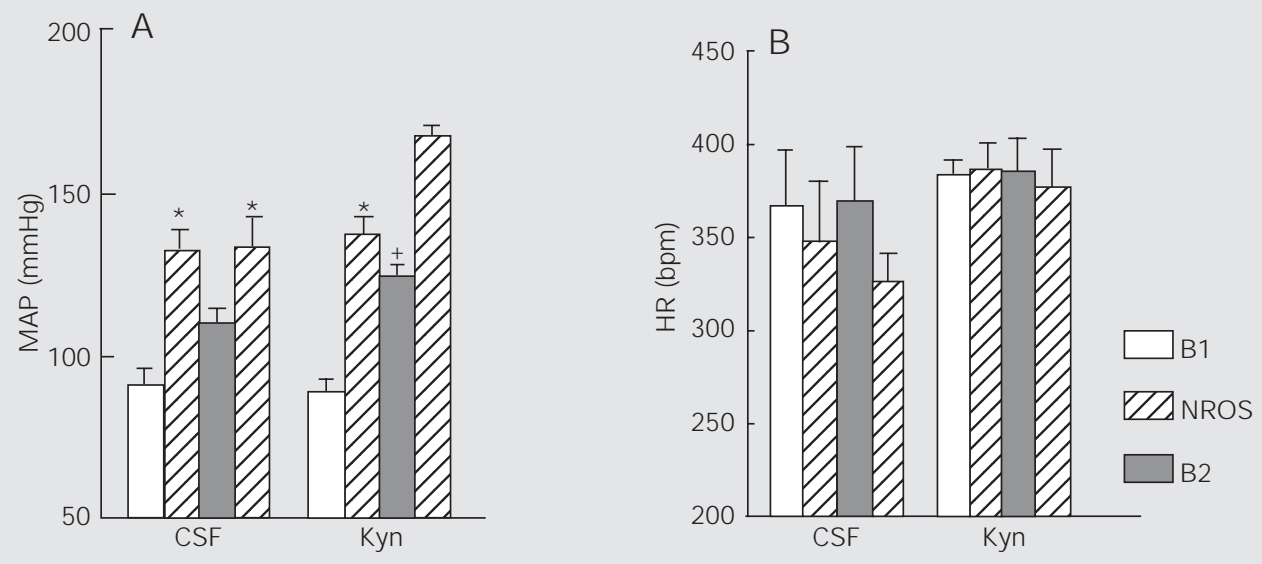

Figure 5. Effect on mean arterial blood pressure (MAP; panel A) and heart rate ( $H R$; panel $B$ ) of bilateral microinjections of cerebrospinal fluid (CSF, $200 \mathrm{nl}$ ) or kynurenic acid (Kyn, $2.7 \mathrm{nmol} /$ $200 \mathrm{nl}$ ) within the caudal ventrolateral medulla and effects of electrical nucleus raphe obscurus stimulation (NROS). B1, baseline values; B2, post-drug baseline values. Data are reported as means \pm SEM for 7 rats. $+\mathrm{P}<0.05$ for $\mathrm{B} 2$ compared to $\mathrm{B} 1$ and $* \mathrm{P}<0.01$ compared to preceding baseline value, B1 (ANOVA). 
Figure 6. A, Tracings from one rat showing the cardiovascular and respiratory responses to nucleus raphe obscurus (NRO) stimulation $(10 \mathrm{~s}$ at $100 \mathrm{~Hz}, 60$ $\mu \mathrm{A}$, and 1-ms pulse duration) before and after bilateral microinjection of kynurenic acid (Kyn, $2.7 \mathrm{nmol} / 200 \mathrm{nl}$ ) within the caudal pressor area (CPA). BP, pulsatile blood pressure; MAP, mean arterial $\mathrm{BP} ; \mathrm{HR}$, heart rate; Resp, respiration. The triangles denote stimulations, and the arrow indicates microinjection. B, The left representative section shows the location of the NRO stimulation site. The illustration on the right shows the injection site within the CPA. after NRO stimulation mediated by bilateral Kyn microinjections within the CPA are shown in Figure 6. BP fell, HR was reduced and Kyn also induced respiratory arrest. Bilateral mi-

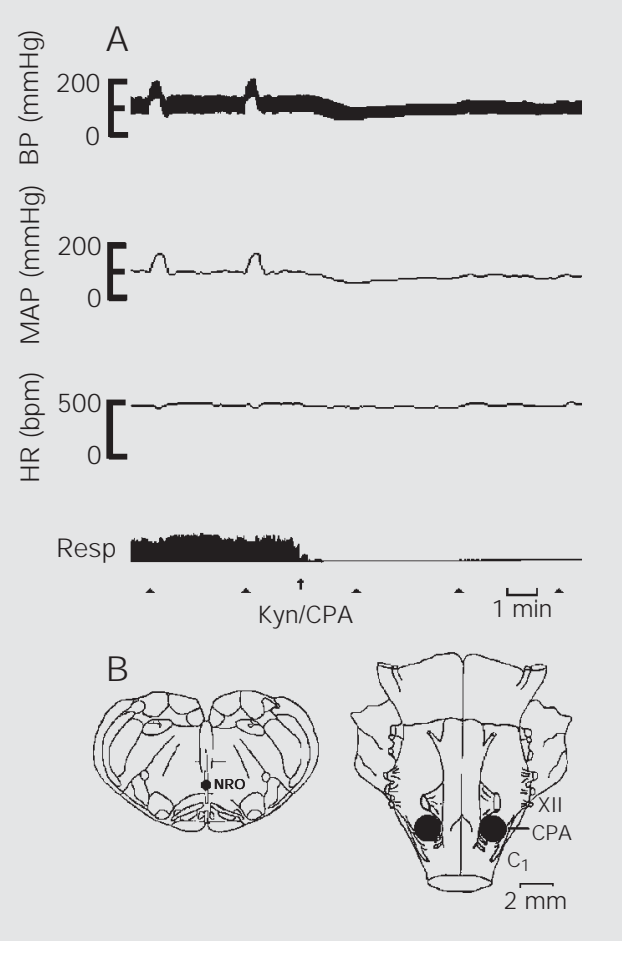

Figure 7. Effect on mean arterial blood pressure (MAP; panel A) and heart rate (HR; panel $B$ ) of bilateral microinjections of cerebrospinal fluid (CSF, $200 \mathrm{nl}$ ) or kynurenic acid (Kyn, $2.7 \mathrm{nmol} /$ $200 \mathrm{nl})$ within the caudal pressor area, and effects of electrical nucleus raphe obscurus stimulation (NROS). B1, baseline values; B2, post-drug baseline values. Data are reported as means \pm SEM for 6 rats. ${ }^{+} \mathrm{P}<0.01 \mathrm{com}$ paring $\mathrm{B} 2$ with $\mathrm{B} 1$ and $* \mathrm{P}<0.01$ compared to preceding baseline values (ANOVA).

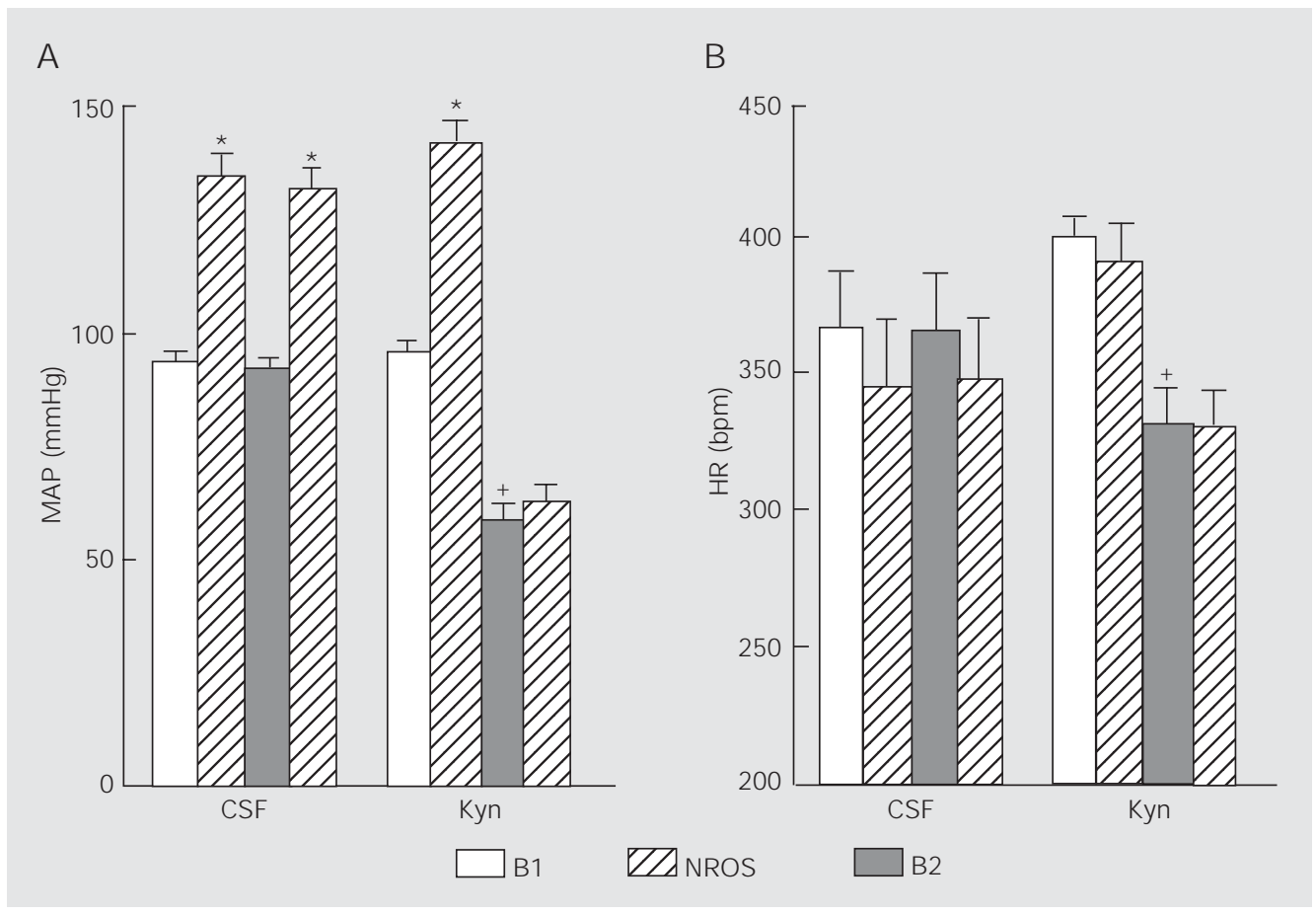

croinjections of Kyn within the CPA significantly reduced both basal MAP (before Kyn = $96 \pm 2$, after Kyn $=59 \pm 4 \mathrm{mmHg}, \mathrm{P}<0.01, \mathrm{~N}$ $=7$; Figure 7), and the pressor response to $\mathrm{NRO}$ stimulation $(\triangle \mathrm{MAP}=+46 \pm 4 \mathrm{mmHg}$ before Kyn, $+4 \pm 2 \mathrm{mmHg}$ after Kyn, $\mathrm{P}<0.01$ ), while the vehicle (CSF) had no effect on either basal parameters (MAP before $\mathrm{CSF}=93 \pm 3$, after $\mathrm{CSF}=92 \pm 2 \mathrm{mmHg}, \mathrm{N}=6$ ), or $\mathrm{NRO}$ stimulation ( $\triangle \mathrm{MAP}$ before $\mathrm{CSF}=+41 \pm 4$, after $\mathrm{CSF}=+40 \pm 4 \mathrm{mmHg}, \mathrm{N}=6$ ).

Basal HR was significantly reduced by Kyn microinjection (control $=400 \pm 7$, after Kyn $=331 \pm 14$ bpm, $\mathrm{P}<0.01, \mathrm{~N}=7$; Figure 7) while CSF induced no obvious change in baseline HR (before Kyn $=367 \pm 22$, after Kyn $=366 \pm 22$ bpm, $N=6$ ). The HR response to NRO stimulation was not significantly reduced after Kyn $(\Delta \mathrm{HR}$ before Kyn $=-10 \pm 16$, after Kyn $=-1 \pm 3 \mathrm{bpm}, \mathrm{N}=$ 7) or CSF ( $\triangle$ HR before CSF $=-20 \pm 9$, after $\mathrm{CSF}=-18 \pm 8 \mathrm{bpm}, \mathrm{N}=6)$.

\section{Discussion}

Electrical stimulation has become a use- 
ful tool to study the participation of the NRO in autonomic control in various species $(2,3)$ by permitting a larger sampling rate in each experiment. The weakness of this technique is that it excites not only cell bodies but also fibers passing through the region. In contrast, neurochemical stimulation preferentially stimulates cell bodies. To avoid this problem the stimulation parameters were chosen so as to minimize current spread and activation of fibers of passage. These same stimulation parameters were previously used in the rat and other species in which they were paired with neurochemical stimulation, with the two different techniques yielding similar results (3-5). The present experimental protocol requires a large number of NRO stimulations separated by a short time interval so as to capture the full result of EAA receptor blockade in the different areas of the ventral medulla. These requirements make it difficult to use neurochemical stimulation of the NRO since tachyphylaxis will limit the number of successive doses of EAA that can be administered and will also force the experimenter to markedly increase the time interval between doses. In view of these limitations, we decided to use electrical stimulation in our experimental protocol.

As stated before, the present study was designed to evaluate the role of EAA receptors of the VLM in the cardiovascular responses to electrical NRO stimulation in the rat. Previous results have suggested that functional integrity of the RVLM is essential to obtain pressor responses evoked by electrical NRO stimulation (15) and that the NRO does not project directly to the IML $(12,13)$. A particularly dense anatomical projection from the NRO to RVLM has been demonstrated $(14,27)$. The cited authors suggest that these projections are mainly serotonergic but do not provide evidence for their function.

EAA receptors within the RVLM do not participate in the pressor responses to NRO stimulation since bilateral microinjections of Kyn (an antagonist of ionotropic EAA receptors) into the RVLM did not block the effects of NRO stimulation activity, although they blocked the HR responses to NRO stimulation, demonstrating that these receptors were probably involved in cardiac regulation following NRO stimulation. It was not clear if HR responses were due to direct NRO cell stimulation or to a secondary reflex response evoked by the baroreflex or the chemoreflex. Dreteler et al. (7) observed mild bradycardia in response to electrical NRO stimulation, which was often associated with the baroreflex. On the other hand, Amano et al. (28) and Koshiya et al. (29) demonstrated that bilateral microinjection of Kyn into the RVLM blocked the sympathetic chemoreflex response but left the sympathetic baroreflex response intact. Also, glutamate microinjection into the NRO resulted in a decrease in BP and HR in rabbits (8). Therefore it is possible that NRO neurons can inhibit cardiac sympathetic activity directly or indirectly within the RVLM without affecting the pressor responses. This differential activation has been previously demonstrated when the NRO is stimulated (30). Nevertheless, the changes in HR observed could also be due to activation of the nucleus ambiguus and or the peri-ambiguus region by NRO stimulation.

Another possibility tested was that the effects of electrical NRO stimulation were mediated by EAA receptors within the CVLM or CPA. The results showed that, despite the CVLM-mediated sympathoinhibitory activity on the RVLM (20), the EAA receptors were not involved in the NRO responses. However, they indicated that the pressor response induced by NRO stimulation in anesthetized rats is mediated by ionotropic EAA receptors in the CPA. Preliminary studies from our laboratory have demonstrated anatomical projections of the NRO to the CPA (31), suggesting that EAA receptors in the CPA play a role in the expression of the pressor response to electrical NRO stimula- 
tion. These results agree with other studies showing that the CPA is involved in cardiovascular control in anesthetized rats $(22,24$, 26). However, the precise nature of this participation is not clear. One such possibility was proposed by Natarajan and Morrison (26), who demonstrated a pathway from CPA to RVLM involving sympathoexcitatory neurons in the vicinity of the CVLM. The present study suggests the existence of a pathway from CPA to RVLM mediating the pressor response elicited by NRO activation, but the precise nature of these projections has not been fully identified.

\section{References}

1. Adair J R, Hamilton BL, Scappaticcika KA, Helke CJ \& Gillis RA (1977). Cardiovascular responses to electrical stimulation of the medullary raphe area of the cat. Brain Research, 128: 141-145.

2. Yen CT, Blum PS \& Spath J A (1983). Control of cardiovascular function by electrical stimulation within the medullary raphe region of the cat. Experimental Neurology, 79: 666-679.

3. Futuro Neto HA, Silva SR, Dantas MA \& Gilbey MP (1990). A comparison of the effects of stimulation within the raphe nuclei on arterial BP in the anesthetized rabbit and rat. Acta Physiologica et Pharmacologica Latinoamericana, 40: 175-184.

4. Faria MGC, Dantas MA \& Futuro-Neto HA (1996). Pressor effects elicited by stimulation within the medullary raphe nuclei of the golden hamster (Mesocricetus auratus). Brazilian J ournal of Medical and Biological Research, 29: 533-540.

5. Almada GL, Pires J GP, Dantas MA \& Futuro Neto HA (1997). Pressor effects elicited by stimulation within the medullary raphe nuclei of the guinea pig (Cavia porcellus). Acta Physiologica, Pharmacologica et Therapeutica Latinoamericana, 47: 229-236.

6. Kuhn DM, Wolf WA \& Lovenberg W (1980). Pressor effects of electrical stimulation of the dorsal and median raphe nuclei in anesthetized rats. J ournal of Pharmacology and Experimental Therapeutics, 214: 403-409.

7. Dreteler GA, Wouters W, Saxena PR \& Ramage AG (1991). Pressor effects following microinjection of $5-\mathrm{HT}_{1 \mathrm{~A}}$ receptor agonists into the raphe obscurus of the anaesthetized rat. British J ournal of Pharmacology, 102: 317-322.

8. Coleman MJ \& Dampney RA (1995). Powerful depressor and sympathoinhibitory effects evoked from neurons in the caudal raphe pallidus and obscurus. American J oumal of Physiology, 268: R1295R1302.
9. Amendt K, Czachurski J, Dembowsky K \& Seller H (1979). Bulbospinal projections to the intermediolateral cell column: a neuroanatomical study. J ournal of the Autonomic Nervous System, 1: 103-117.

10. Loewy AD (1981). Raphe pallidus and raphe obscurus projections to the intermediolateral cell column in the rat. Brain Research, 222: 129-133.

11. Gilbey MP, Futuro Neto HA \& Zhou SY (1995). Respiratory-related discharge pattems of caudal raphe neurons projecting to the upper thoracic spinal cord in the rat. J oumal of the Autonomic Nervous System, 50: 263-273.

12. Bacon SJ , Zagon A \& Smith AD (1990). Electron microscopic evidence of a monosynaptic pathway between cells in the caudal raphe nuclei and sympathetic preganglionic neurons in the rat spinal cord. Experimental Brain Research, 79: 589602.

13. Zagon A (1993). Innervation of serotonergic medullary raphe neurons from cells of the rostral ventrolateral medulla in rats. Neuroscience, 55: 849-867.

14. Zagon A (1995). Internal connections in the rostral ventromedial medulla of the rat. J ournal of the Autonomic Nervous System, 53: 43-56.

15. Campos J r RR, Futuro Neto HA \& Guertzenstein PG (1993). Role of the rostral ventrolateral medulla in the pressor response to stimulation of the nucleus raphe obscurus. Brazilian J oumal of Medical and Biological Research, 26: 623-631.

16. Guertzenstein PG \& Silver A (1974). Fall in BP produced from discrete regions of the ventral surface of the medulla by glycine and lesions. J oumal of Physiology, 242: 489-503.

17. Futuro Neto HA, Dantas MA, Gilbey MP \& Pires J GP (1996). A study of the nature of the projections from nucleus raphe obscurus to the ventrolateral medulla. Society for Neuroscience Abstracts, 22: 954.

18. Bisset GW, Feldberg W, Guertzenstein
PG \& Rocha e Silva J r M (1975). Vasopressin release by nicotine: the site of action. British J ournal of Pharmacology, 54: 463-474.

19. Feldberg W \& Guertzenstein PG (1976). Vasodepressor effects obtained by drugs acting on the ventral surface of the brain stem. J oumal of Physiology, 258: 337355.

20. Cravo SL \& Morrison SF (1993). The caudal ventrolateral medulla is a source of tonic sympathoinhibition. Brain Research, 621: 133-136.

21. Feldberg W \& Guertzenstein PG (1986). Blood pressure effects of leptazol applied to the ventral surface of the brainstem of cats. J ournal of Physiology, 372: 445-456.

22. Gordon FJ \& McCann LA (1988). Pressor responses evoked by microinjections of L-glutamate into the caudal ventrolateral medulla of the rat. Brain Research, 457: 251-258.

23. Possas OS, Campos Jr RR, Cravo SL, Lopes OU \& Guertzenstein PG (1994). A fall in arterial BP by blockade of the caudalmost ventrolateral medulla: the caudal pressor area. J ournal of the Autonomic Nervous System, 49: 235-245.

24. Campos Jr RR, Possas OS, Cravo SL, Lopes OU \& Guertzenstein PG (1994). Putative pathways involved in responses evoked from the caudal pressor area. Brazilian J ournal of Medical and Biological Research, 27: 2467-2479.

25. Campos J r RR \& McAllen RM (1999). Tonic drive to sympathetic premotor neurons of rostral ventrolateral medulla from caudal pressor area neurons. American J ournal of Physiology, 276: R1209-R1213.

26. Natarajan M \& Morrison SF (2000). Sympathoexcitatory CVLM neurons mediate responses to caudal pressor area stimulation. American J oumal of Physiology, 279: R364-R374.

27. Nicholas AP \& Hancock MB (1990). Evidence for projections from the rostral medullary raphe onto medullary catechol- 
amine neurons in the rat. Neuroscience Letters, 108: 22-28.

28. Amano M, Asari T \& Kubo T (1994). Excitatory amino acid receptors in the rostroventrolateral medulla mediate hypertension induced by carotid body chemoreceptor stimulation. Naunyn-Schmiedeberg's Archives of Pharmacology, 349: 549-554.
29. Koshiya N, Huangfu D \& Guyenet PG (1993). Ventrolateral medulla and sympathetic chemoreflex in the rat. Brain Research, 609: 174-184.

30. Futuro Neto HA \& Coote JH (1982). Desynchronised sleep-like pattern of sympathetic activity elicited by electrical stimulation of sites in the brainstem. Brain Research, 252: 269-276.
31. Silva NF, Campos J r RR, Araujo GC, Bergamaschi CT, Pires J GP, Dantas MA \& Futuro Neto HA (1998). Demonstration of projections from nucleus raphe obscurus to the caudal pressor area of the ventral medulla in the rat. Society for Neuroscience Abstracts, 24: 627. 